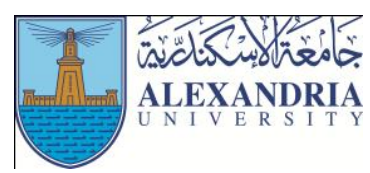

\title{
The Effect of a Therapeutic Recreational Program on Improving the Social Intelligence of Schizophrenia Patients
}

\author{
Eman Abd Elaziz Abd Elwahab ${ }^{1}$ \\ ${ }^{1}$ Lecturer at the Recreation Department, Faculty of Physical Education for Girls, Alexandria University, Egypt
}

\begin{abstract}
:
Schizophrenia is one of the most important modern diseases in societies, and it is a mental illness that appears in the form of confusion and incompatibility between the different functions of the human soul, and its treatment begins with medical treatment, followed by psychological and social treatments by developing the ability of realizing social relations and improving social intelligence. Recreation contributes in achieving psychological balance and developing social intelligence by practicing the recreational activities that provide a healthy pattern of life as well as physical, mental and social education. This study aims at identifying the effect of therapeutic recreational program on improving the social intelligence of schizophrenia patients. A therapeutic recreational program was applied for 16 sessions on a sample included schizophrenia patients from El-Maamoura Psychiatric Hospital in Alexandria. The researcher used the social intelligence scale. It was found that the therapeutic recreational program has improved the social intelligence by $63.55 \%$ for the schizophrenia patients of El-Maamoura Psychiatric Hospital in Alexandria governorate.
\end{abstract}

\section{Introduction and research problem:}

$\mathrm{T}$ The modern age with all of its variables, psychological and economic pressures and social life complexities which led to many mental diseases (6:202), one of which the most important modern diseases is schizophrenia, which receives special attention from scientists as one of the most widespread psychological diseases in societies, which affects the behavior and social relations (17:11).

Schizophrenia is a mental illness that appears in the form of confusion and incompatibility between the different functions of the human soul (thinking, conscience, and behavior). These symptoms appear as confusion in the thinking process, in addition to the emergence of motor and behavioral symptoms that lead to the person is confined and lives in his/her own world, which in turn affect the individual's life, family and community (11:9).

Schizophrenia occurs due to several factors that lead to certain changes in the brain, including genetic factors, pregnancy and giving birth, family problems, life situations, drug abuse and addiction (17:35), and as the scientific research which is concerned with the brain cells science increases, the information of the causes of schizophrenia is constantly growing and developing. The most important causes of schizophrenia are classified as organic, biological, psychological and social causes. $(11: 10)$

The treatment of schizophrenia is available despite the difficulties that may occur at the beginning of treatment. Treatment is being done in the clinics, while some cases may require admission to a specialized hospital where the first stage begins with medical treatment and then gets followed by the psychological and social treatment to rehabilitate the patient to practice his/her life closer to the normal situation. (17:56)

Schizophrenia undergoes stages of treatment starting with medication that reduces the positive and negative symptoms (19), and then the psychological therapy to control the symptoms of anxiety, depression and mental disability through analytical and behavioral treatments that rely on training programs to help the schizophrenia patient get involved with the society, then the social treatment that aims at rehabilitating the patient through the posttreatment centers to help him/her integrate professionally and socially as well as exploiting the psychological potentials. (22) (4:66)

Social rehabilitation of schizophrenia patients is carried out according to clear goals to achieve the psychological and social compatibility in order to provide them with the skills and experiences that enable them to integrate into 
the social life $(15: 157)$. This is accomplished by developing the ability of understanding the social relationships and understanding and interacting with the surrounding people leading to social harmony and individual' success in his/her social life, which is called social intelligence (7).

Social intelligence is linked to many mental abilities that deal with social content to understand the feelings and behaviors of others in different social situations through a set of skills that help the individual solve social problems and achieve useful social outcomes (21). Social intelligence is divided into behavioral aspect (extent of the individual's efficiency of interacting with others) and cognitive aspect (awareness, imagination and social knowledge) (27). It also has many components such as social expression, social sensitivity, social control, social information processing, social skills, social awareness, and social emotion (23) (25).

Recreation can contribute to the achievement of psychological balance and the development of social intelligence through recreational activities that provide a healthy pattern of life, physical and mental education, selfconfidence and social development. We can say that recreational activities are one of the most important psychological and social causes due to their structures which include communication and social relations (28:259).

Recreation and recreational activities are necessary for mental and physical health, and help improving rehabilitation, learning communication skills, solving psychosocial and social problems and improve the behavior (18:89). Recreation is not limited to a certain category but extends to the provision of recreational services for positive intervention to modify the physical, emotional and social behaviors (13:39).

Recreation has a notable role in the programs of various mental illnesses treatment and helps patients to supplement their lives in health and wellness, also recreational activity is a factor of treatment and protection and creates a better atmosphere for nursing, medical care and patient satisfaction. Therapeutic recreation helps the patient to benefit from the long period spent in hospital because the activities which he/she practice contributes to the development of personal and social friendly relations and increases the ability to participate socially (8:341).

Therapeutic recreational services contribute positively to the patients and help improving mental health and increase the various social and physical skills (24:33). Therapeutic recreation is designed to make individuals happier, satisfied, get adapted with the community and help the patient to agree with the living at the hospital to be more receptive to the treatment and this helps the patient to be more confident and increase the social abilities (8:342).

From the previous information, it is obvious that the schizophrenia patient needs psychological and social care in the rehabilitation stage, which requires the development of different psychological and social aspects of social intelligence, which is greatly weakened by the disease for a long time at the therapeutic institution. The researcher here noticed that there is a lack in the studies that concern with the role of recreation and therapeutic recreational programs in the treatment and rehabilitation of psychiatric patients, especially the schizophrenia patients, therefore she intended through conducting this study to apply a therapeutic recreational program to improve the social intelligence of the schizophrenia patients at El-Maamoura Psychiatric Hospital in Alexandria.

\section{Research objective:}

The research aims at identifying the effect of a therapeutic recreational program on improving the social intelligence of schizophrenia patients.

\section{Research hypotheses:}

The therapeutic recreational program positively affects the improvement of social intelligence of schizophrenia patients.

\section{Research procedures:}

The researcher used the experimental approach using an experimental group and a control group. The study was conducted during the period from 1/10/2016 until 30/1/2017.

\section{Research sample:}

The sample was selected from schizophrenia patients who were under treatment at El-Maamoura Psychiatric Hospital in Alexandria Governorate, and they were 20 patients aged 20-35 years and were divided into two groups (experimental group consisting of 10 patients who had the proposed therapeutic recreational program applied to them using pre- and post-measurements), and (control group consisting of 10 patients who were treated with the hospital's treatment program using only the postmeasurement)

\section{Data collecting tools:}

The researcher used the study of El-Sayed Abou Hashem (2008) (3) and the study of Silvera et al (2001) (25) in constructing the Social Intelligence Scale (Appendix 1). 
The terms of the scale were formulated according to the research sample (60 phrases) divided into 6 aspects: Social Information Processing, Social Skills, Social Awareness, Social Self-efficacy, Social Empathy, Social Problem Solving, and there are five answers for each of the questions (always, often, sometimes, rarely, never).
Validity and reliability were calculated on a sample of schizophrenia patients included 10 patients of the same research community as follows:

I) Validity: validity of the social intelligence scale of schizophrenia patients was calculated using the validity of internal consistency as shown in table (1).

Table (1)

Correlation coefficient between the aspects and the total score of the social intelligence scale for the schizophrenia patients $(n=10)$

\begin{tabular}{|c|c|c|}
\hline S. & Social intelligence scale for the schizophrenia patients & Correlation coefficient \\
\hline 1 & Social Information Processing & $0.911^{* *}$ \\
\hline 2 & Social Skills & $0.987^{* *}$ \\
\hline 3 & Social Awareness & $0.985^{* *}$ \\
\hline 4 & Social Self-efficacy & $0.956^{* *}$ \\
\hline 5 & Social Empathy & $0.985^{* *}$ \\
\hline 6 & Social Problem Solving & $0.940^{* *}$ \\
\hline
\end{tabular}

Significance of the Pearson Corr. the level of $0.05=0.632$

Table (1) shows that there is a significant difference in the value of the $(\mathrm{P})$ correlation coefficient between the aspect's score and the total score of the scale, where the values ranged between $(0.911$ and 0.987$)$ confirming the validity of the social intelligence scale for the schizophrenia patients before application to the main research sample.

II) Reliability: reliability of the social intelligence scale of schizophrenia patients was calculated using the Cronbach's Alpha coefficient as shown in table (2).

Table (2)

Reliability coefficient of the social intelligence scale for the schizophrenia patients $(n=10)$

\begin{tabular}{|c|c|c|}
\hline S. & Social intelligence scale for the schizophrenia patients & Cronbach's Alpha coefficient \\
\hline 1 & Social Information Processing & 0.973 \\
\hline 2 & Social Skills & 0.941 \\
\hline 3 & Social Awareness & 0.983 \\
\hline 4 & Social Self-efficacy & 0.984 \\
\hline 5 & Social Empathy & 0.988 \\
\hline 6 & Social Problem Solving & 0.989 \\
\hline & Total score & 0.995 \\
\hline
\end{tabular}

Table (2) shows that the values of Cronbach's Alpha coefficient reliability for the scale's aspects ranged from (0.941 and 0.989) and the total score was 0.995, and these values were high, which confirms the reliability of the social intelligence scale for the schizophrenia patients prior to application to the main research sample.

\section{Main Study:}

The pre-measurement was applied on the experimental group in the period from 1-13/10/2016, and the therapeutic recreational program was applied for two months during the period from 15/10/2016 until 15/12/2016, while the control group used the hospital rehabilitation program, then the post-measurement was applied on the two groups in the period from 17-29/12/2016.

\section{Proposed therapeutic recreational program: Attachment (2)}

The researcher identified the suitable athletic recreational, social and technical activities for the research sample, which helps to improve the social intelligence of the schizophrenia patients and to achieve the objectives of the therapeutic recreation program. The program was implemented for two months with two sessions a week and a total of 16 therapeutic recreational sessions. The preliminary part (15 minutes) aims to prepare the patients to accept the participation in the recreational activities, while the main part (90 minutes) where the recreation activities that help improve the social intelligence of schizophrenia patients are carried out, and the final part (15 minutes) aims to calm and bring pleasure in the hearts 
of the patients to accept participation in the following sessions.

\section{Statistical treatments:}

The data was processed using IBM SPSS Statistics 20 to obtain the mean, standard deviation, percentage, Pearson correlation, Cronbach's Alpha, paired sample T test, independent sample T test, and effect size.

\section{Presentation of the results:}

Table (3)

Percentage of improvement, effect size and calculated $(t)$ value between the pre- and post-measurements of the experimental group for the aspects of the social intelligence scale for schizophrenia patients $(n=10)$

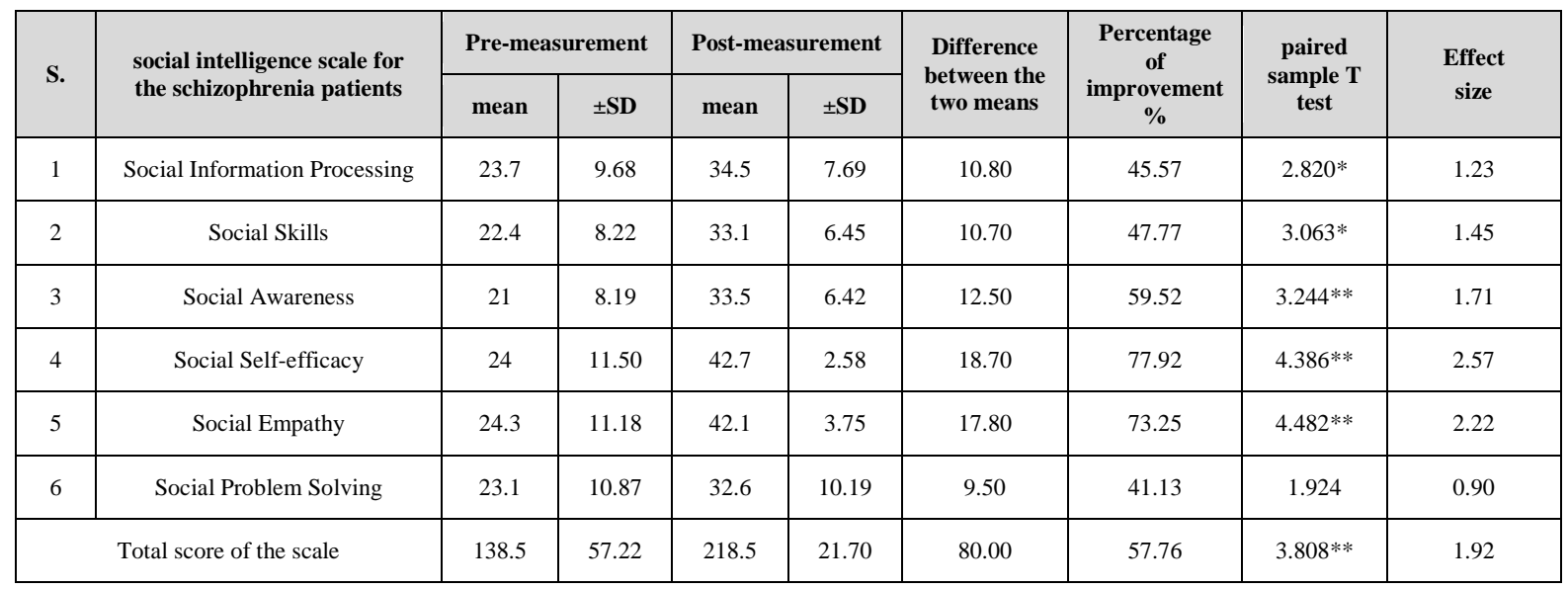

*"T" test value significant at the level of $0.05=2.262$, Effect size significance, High = greater than 0.8

Figure (1)

Arithmetic mean between the pre- and post-measurements of the experimental group for the aspects of the social intelligence scale for schizophrenia patients

\section{$\square$ Pre-measurement $\square$ Post-measurement}

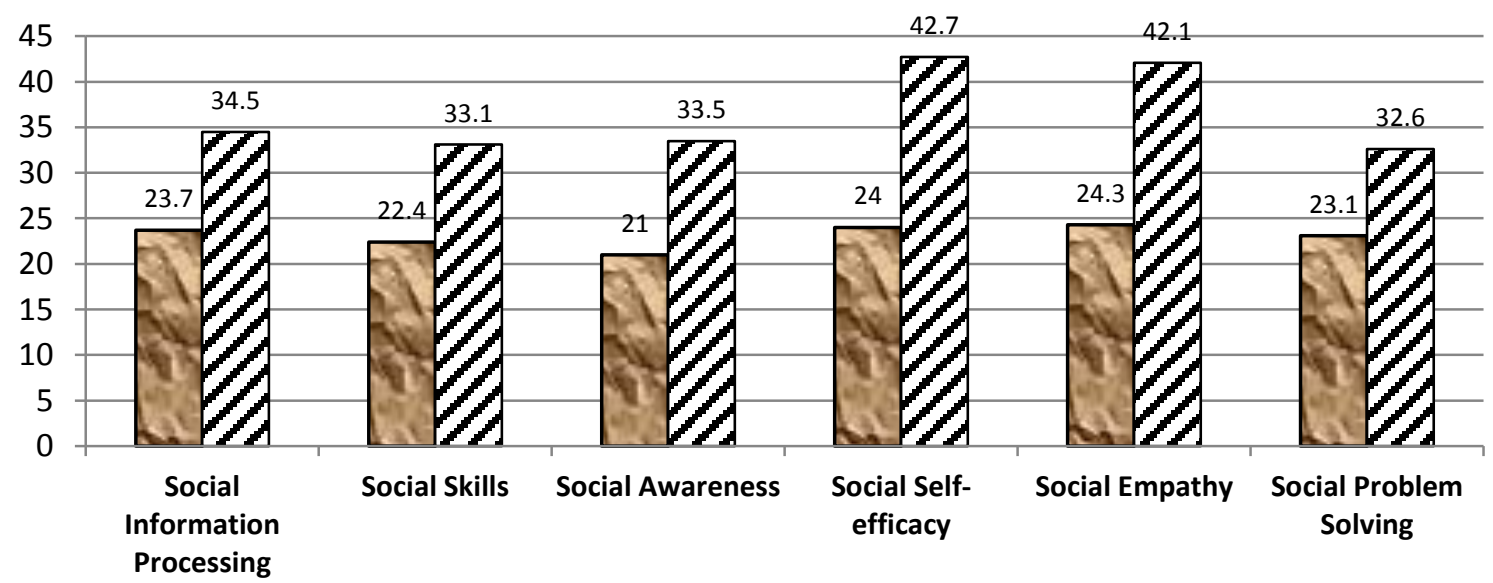

Table (3) and Figure (1) show that there are significant differences in the calculated " $t$ " value between the preand post-measurements of the experimental group in the score of the social intelligence scale with an improvement percentage of $75.76 \%$, while the improvement in percentage of the scales' aspects ranged between $41.13 \%$ and $77.92 \%$ in favor to the post-measurement, while the effect of the therapeutic recreational program was high in all aspects of the scale. 
Table (4)

Difference Percentage and calculated ( $t$ ) value between the experimental and control groups of the post-measurement for the aspects of the social intelligence scale for schizophrenia patients

\begin{tabular}{|c|c|c|c|c|c|c|c|c|}
\hline \multirow[t]{2}{*}{ S. } & \multirow[t]{2}{*}{$\begin{array}{l}\text { social intelligence scale for } \\
\text { the schizophrenia patients }\end{array}$} & \multicolumn{2}{|c|}{$\begin{array}{c}\text { Exp. group } \\
\quad \mathbf{N}=10\end{array}$} & \multicolumn{2}{|c|}{$\begin{array}{c}\begin{array}{c}\text { Control } \\
\text { group }\end{array} \\
\mathbf{N}=10 \\
\end{array}$} & \multirow[t]{2}{*}{$\begin{array}{l}\text { Difference between the } \\
\text { two means }\end{array}$} & \multirow[t]{2}{*}{$\begin{array}{l}\text { Percentage of } \\
\text { improvement } \%\end{array}$} & \multirow[t]{2}{*}{$\begin{array}{l}\text { Independent } \\
\text { Sample T test }\end{array}$} \\
\hline & & mean & $\pm \mathrm{SD}$ & mean & \pm SD & & & \\
\hline 1 & Social Information Processing & 34.5 & 7.69 & 21.5 & 11.64 & 13.00 & 60.47 & $2.95 * *$ \\
\hline 2 & Social Skills & 33.1 & 6.45 & 23 & 7.76 & 10.10 & 43.91 & $3.16^{* *}$ \\
\hline 3 & Social Awareness & 33.5 & 6.42 & 23.9 & 8.61 & 9.60 & 40.17 & $2.83 *$ \\
\hline 4 & Social Self-efficacy & 42.7 & 2.58 & 23.5 & 9.02 & 19.20 & 81.70 & $6.47 * *$ \\
\hline 5 & Social Empathy & 42.1 & 3.75 & 22.6 & 9.51 & 19.50 & 86.28 & $6.03 * *$ \\
\hline 6 & Social Problem Solving & 32.6 & 10.19 & 19.1 & 5.09 & 13.50 & 70.68 & $3.75^{* *}$ \\
\hline & Total score of the scale & 218.5 & 21.70 & 133.6 & 30.56 & 84.90 & 63.55 & $7.16^{* *}$ \\
\hline
\end{tabular}

*"T" test value significant at the level of $0.05=2.101$

Figure (2)

Arithmetic mean of the post-measurement of the experimental and control groups for the aspects of the social intelligence scale for schizophrenia patients

\section{$\square$ Exp.group $\square$ Control group}

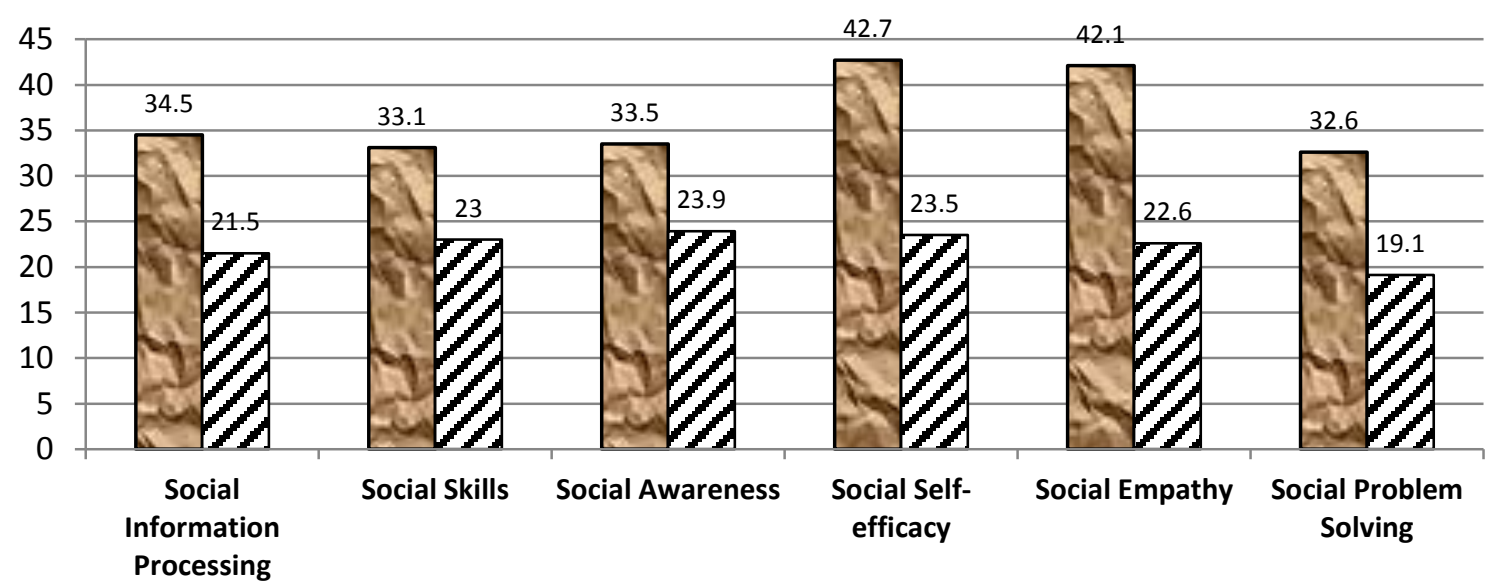

Table (4) and Figure (2) show that there are significant differences in the calculated " $t$ " value between the experimental and control groups in the post-measurement in the score of the social intelligence scale with a difference percentage of $63.55 \%$, while the percentage differences of the scales' aspects ranged between $40.17 \%$ and $86.28 \%$ in favor to the experimental group.

\section{Discussion of the results:}

Table (3) shows that the proposed therapeutic recreational program improved the social intelligence by $57.76 \%$ and improved the aspects of social intelligence with percentages ranged between $(41.13 \%$ and $77.92 \%)$, where "Social Self-efficacy" had the greatest percentage of improvement, then "Social Empathy", and "Social
Awareness", while "Social Problem Solving" had the lowest percentage of improvement. Effect size was high, and this indicates that therapeutic recreation works on improving the social intelligence of the schizophrenia patients.

Table (4) shows that there was an improvement in the social intelligence of the schizophrenia patients who had the therapeutic recreational program applied (experimental group) with a percentage of $63.55 \%$ exceeding the patients who did not go through the therapeutic recreational program (control group) during the rehabilitation stage, and shows also an improvement in the social intelligence aspects that ranged between $(40.17 \%$ and $86.28 \%$ ), where "Social Empathy" had the highest percentage of improvement, then "Social Self-efficacy", "Social 
Problem Solving", and "Social Information Processing", while "Social Awareness" and "Social Skills" had the lowest percentages of improvement. This confirms that recreation helps in improving the social intelligence of schizophrenia patients.

These results are consistent with the results of some previous studies which focused on the effect of physical exercise on schizophrenia patients such as the study of Eslah Shafey (2004) that confirmed that the participation of schizophrenia patients in physical exercises has a positive effect in improving their psychological state, enhancing their cooperation abilities and reducing their emotional isolation as well. (2) Social treatment for the schizophrenia patients aims to avoid withdrawal and isolation as well as giving interest in social activity to connect the patient to the reality and reduce his/her preoccupation with himself/herself, such as treatment by work, reading books, acting, drama, art, painting and photography (1:605).

There is no doubt that practicing the recreational activities helps the patient to be more confident and adapt with the community, as the diversity of activities and different games is considered of the important means of social interaction, whether it was negative by watching or positive by practice, such as therapeutic recreation, which helps the individual to restore the psychological balance, increase self-confidence and self-esteem, develop cooperation with friends and the surrounding individuals and stop negative thinking about self and integration into society (8:204).

Social intelligence is the ability to understand others' behavior and to be aware of the interpersonal relations and social self-efficacy in the different situations as well as social participation with others and solving social problems, leading to social harmony and the success of the individual in his/her social life (3:170).

Sympathy is one of the social intelligence components and means a state of positive feeling among people and makes them share a sense of attachment, as good behaviors develop empathy, which leads to the acquisition of personal benefits and maintain strong social relations (10:63). Self-esteem is an experience passed on by the individual to others, and the practice of recreational activities provides a healthy pattern of life, selfaffirmation and social development. It can be said that recreational activities are one of the most important psychological causes due to its structure which involve communication and social relations (28:259). Therapeutic recreation helps the patient to achieve emotional and social needs, reduce the consequences of social isolation, raise morale and encourage patients to express themselves and show and develop their hobbies and acquire a sense of satisfaction and learn useful social skills and experiences (8:343).

The basic needs of man do not change either by suffering from a physical or mental disability as the patient needs to feel safe and express himself/herself, while mental and emotional disorders lead to fear and nervous pressure and when the nervous pressure accumulate we find that the recreational activity is the way to salvation from these pressures. Therapeutic recreation contributes to the treatment by preparing the patient and allowing him to gain experience and physical, psychological and social skills through practicing some types of the suitable recreational activities $(5: 112)$.

The results show improvement in social awareness and social problems solving, and awareness means the understanding of the self and the surrounding individuals when interacting with them through different situations and it is the basis of all knowledge (14:22), while social awareness is the ideas, opinions and social feelings that people have and reflect their objective reality (9:189). There is a relationship between social intelligence and awareness and social problems solving where the individual uses ideas and means by addressing the data to solve the problem. The results also show that recreation has increased social awareness and the ability to solve the social problems of schizophrenia patients $(16: 116,148)$.

Practicing recreational activities gives pleasure to the individual and grows the desire to build friendships and human relationships as well as using mental abilities to help others (6:106). Recreation is essential for mental and physical health which helps individuals to rehabilitate within the society, to modify behavior and to solve problems by participating in psychosocial activities (18:89) (5:113). Therapeutic recreation aims at providing help in the treatment and rehabilitation of patients, adjusting behavior and adapting to society, and the therapeutic recreational program helps the patients to restore their physical fitness and contribute to upgrading their mental abilities and improving their creative abilities (16:149).

The results shows an improvement in the social information processing and social skills, which is the ability to read expressions from others and transform them into behaviors, experiences and social skills, and social skill is the individual's ability of emotional and social expression and receiving the others' emotions and addressing them with awareness using different forms of social interaction and self-presentation appropriately in 
social situations. Schizophrenia patients have poor social performance and deterioration in social skills due to mental disability and cognitive decline due to the long period of illness at the therapeutic institution (20:650). Therefore, we should concern more with the methods and programs that focus on the developing the social skills of schizophrenia patients, especially with the increasing number of this type of patients within the governmental hospitals and the failure of the traditional treatment used by these hospitals (12:28). Recreation promotes social skills by developing the ability to properly process social information through the experiences and skills acquired by the individual as a result of practicing the recreational activities.

Therefore, we should use the modern therapeutic methods during the future care and rehabilitation phase, focusing mainly on social skills using recreation, vocation, or housing activities. This will lead to more fasten the improvement of social and cognitive skills, compared to the general social skills training (26).

According to the results there was an improvement in the social intelligence of the schizophrenia patients, which means that the patients needed the complete care as well as using the methods of help in treatment, such as the therapeutic recreation alongside psychological and social medication, and this confirms that the treatment and rehabilitation of schizophrenia patients by an integrated team which involves the recreational specialist alongside the doctors, nurses and psychologists taking into consideration the social coordination in a way that ensures the benefit of patients at the hospital or the treatment and rehabilitation centers.

The results of the study and its discussion show that recreation, especially therapeutic recreation which is appropriate to the requirements of the schizophrenia patients, led to the improvement of social intelligence by improving its components which are: social empathy, social self-efficacy, social problems solving, social information processing, social skills and social awareness with varied percentage for the schizophrenia patients, so the research hypothesis which says that the therapeutic recreation has a positive effect in improving the social intelligence of schizophrenia patients is confirmed.

\section{Conclusions:}

In the light of the research objectives, the following were concluded:

1- The therapeutic recreational program improved the social intelligence of the schizophrenia patients by $63.55 \%$ at El-Maamoura Psychiatric Hospital in Alexandria Governorate.

2- The therapeutic recreational program improved social empathy by $86.28 \%$, social self-efficacy by $81.70 \%$, social problems solving by $70.68 \%$, social information processing by $60.47 \%$, social skills by $43.91 \%$, and social awareness by $40.17 \%$ for the schizophrenia patients in ElMaamoura Psychiatric Hospital in Alexandria Governorate.

\section{Recommendations:}

In the light of the research results, the researcher recommends the following:

1- Applying the proposed therapeutic recreational program on schizophrenia patients at the treatment and rehabilitation centers for schizophrenia patients in the Arab Republic of Egypt.

2- Giving more interest in the therapeutic recreation in the rehabilitation programs for mental patients at the specialized hospitals and centers.

3- Officials should concern with providing the facilities, tools, equipment and recreational facilities to the hospitals, government clinics and rehabilitation centers.

\section{References:}

1- Ahmed Ezzat Rageh (1994) Psychological and mental diseases - causes, treatment and side effects, Dar Al Ma'aref, Alexandria.

2- Mohamed Shafey (2004) Effect of physical exercise on some psychological symptoms of schizophrenia patients, master's thesis, Faculty of Physical Education for Girls, Alexandria University.

3- El-Sayed Mohamed Abou-Hashem (2008) Components of social and emotional intelligence and their relational model among the Egyptian and Saudi University Students "Comparative Study", Volume 18, Issue 76, Journal of the Faculty of Education, Benha University

4- Boufulla Boukhamis (2014) linguistic disorders of the schizophrenia patient - cognitive psychology study, Dar Joana for Publishing and Distribution, Cairo.

5- Tahany Abdel-Salam Mohamed (1973) Youth, recreation and life, Anglo-Egyptian Library, Cairo.

6- Tahany Abdel-Salam Mohamed (2001) Recreation and recreational education, Dar Al-Fikr Al-Araby, Cairo. 
7- Hamed Abdel-Salam Zahran (1984) Social psychology, 5th Edition, Book World, Cairo

8- Helmy Ibrahim, Laila El-Sayed Farahat (1998) Physical education and recreation for the disabled, 1st Edition, Dar Al-Fikr Al-Araby, Cairo.

9- Samir Naim Ahmed (2006) Theory in sociology, 10th Edition, Cairo.

10- Adel Abou El-Anwar (2014) Developing and exploiting the skills of social intelligence: How to make your relationship a weapon for your success, Al-Manhal, Cairo

11- Ghada Ahmed Ghazy (2010) How to coexist with the schizophrenia patient, Book Center, Alexandria

12- Fahd Bin Abdullah Bin Aly Al-Dulaim (2006), Social skills of schizophrenia patients and the hypnotized, Volume 4, No. 1, Journal of Arabic Studies in Psychology, Faculty of Education, King Saud University

13- Kariman Kamal Mohamed (2016) A proposed curriculum for therapeutic recreation for the students of the Faculty of Physical Education for Girls, Alexandria University, unpublished $\mathrm{PhD}$ thesis, Faculty of Physical Education for Girls, Alexandria University.

14- Mohamed Saud Al-Arify (1995) Relationship between social awareness and the reduction of the spread of narcotic drugs, master's thesis, Arab Center for Security Studies and Training, King Saud University, Riyadh.

15- Mohamed Sayed Fahmy (2011) Social work and schizophrenia, 1st edition, Dar Al-Wafaa for Printing and Publishing, Alexandria.

16- Mohamed Mohamed El-Hamahemy, Aida Abdel-Aziz (2006) Recreation between theory and practice, 2nd edition, Book Center for Publishing, Cairo.

17- Walid Sarhan (2000) Behaviors 2 (schizophrenia), Dar Majdalawi for Publishing and Distribution, Amman, Jordan.
18- Brenda J, Robertson (2000): The leisure education of incarcerated youth, Acadia university wolf Ville, World leisure association, Volumes 3, No 1. New York.

19- Granger B., (2003) Psychiatry Today: From Diagnosis to Treatment, Paris ed., Odile Jacob.

20- Green, M.F (1996). What are the functional consequences of neuro-cognitive deficits in schizophrenia ? Amercan Journal of Psychiatry (153) pp 321-330

21- Marlowe , H (1986). Social Intelligence : Evidence for Multidimensionality and Construct Independence, Journal of Educational Psychology , 78(1), pp. 52-58.

22- Postel J., Ed (1998) Dictionary of Psychiatry and Clinical Psychopathology, Paris, Larousse - Bordas.

23- Riggio , R , Messamer, J and Throckmorton ,B (1991). Social and Academic Intelligence : Conceptually Distinct But Overlapping Constructs, Personality and Individual Differences, 12(7), pp. 695 - 702 .

24- Robert J Campbell (2009) Campbell's psychiatric dictionary, the definitive dictionary of psychiatry, Oxford University

25- Silvera D., Martinussen M, Dahl T. (2001) The Troms $\varnothing$ Social Intelligence Scale, a self-report measure of social intelligence, Scand J Psychol. ;42(4):313-9.

26- Volker Roder, et al (2002) Development of specific social skills training programmes for schizophrenia patients: results of a multicentre study, Acta Psychiatrica Scandinavica, Volume 105, Issue 5, Pages 363-371

27- Wong, C, Day, J , Maxwell , S and Meara , N (1995) A Multitrait - Multimethod Study of Academic and Social Intelligence in College Students, Journal of Educational Psychology , 87(1), pp. 117-133.

28- Yigiter K., (2013) : Improving the nursing students' assertiveness skills by participating in recreational physical activities, International Journal of Sport Studies. Vol., 3 (3), 258-262. 